\title{
RESPONSABILIDADE CIVIL DO EMPREGADOR: ESPÉCIES
}

\author{
Andréia Delibório, Mári Ângela Pelegríni
}

Universidade do Oeste Paulista - Unoeste/SP, Direito, Presidente Prudente, São Paulo.Emailandreiadeliborio@hotmail.com

\section{RESUMO}

$\mathrm{O}$ artigo analisa a responsabilidade civil na esfera trabalhista quando resulta dano à integridade física do empregado, fruto de culpa patronal. O objetivo do artigo é identificar as teorias que informam este instituto e a predominante, quando os empregadores cometem os chamados ilícitos civis. Demonstra que, havendo os três elementos: nexo, dano e culpa, o dever de indenizar estará presente. $\mathrm{O}$ artigo identifica tais elementos e destaca que a culpa é a que apresenta maior dificuldade de comprovação na justiça. Para identificar se houve negligência, imprudência ou imperícia os juristas se apoiam nas teorias objetiva e subjetiva, como ensina a doutrina civilista e trabalhista nacional. Utilizou-se o método indutivo, partindo do geral, para o particular, com pesquisas bibliográficas. Conclui-se que a teoria subjetiva (que exige prova da culpa) tem sido a mais utilizada pelos juízes, ao contrário da objetiva, usada somente para atividades de alto risco.

Palavras-Chave: Responsabilidade. Civil. Culpa. Subjetiva. Objetiva.

\section{LIABILITY OF THE EMPLOYER: SPECIES}

\begin{abstract}
The article analyzes the civil liability in labor when resulting damage to the employee's physical integrity of employers guilt fruit. The objective of this article is to identify the theories that inform the Institute and the predominant, when employers commit called torts. It shows that, with the three elements: nexus, damage and guilt, the duty to indemnify will be present. The article identifies these elements and highlights the fault that is more difficult to prove in court. To identify whether there was negligence, recklessness or malpractice lawyers rely on objective and subjective theories, as teaches civil law doctrine and national labor. We used the inductive method starting from the general to the particular, literature searches. We conclude that the subjective theory (which requires proof of fault) has been the most used by judges, contrary to the objective, used only for high-risk activities.
\end{abstract}

Keywords: responsibility. Civil. Fault. Subjective. Objective. 


\section{INTRODUÇÃO}

Partindo de uma breve análise dos elementos que compõe a responsabilidade civil (dano, nexo e culpa), identificou-se as teorias existentes e que informam o ordenamento jurídico brasileiro sobre o tema, a saber: objetiva, subjetiva, contratual, extracontratual, direta e indireta.

A responsabilidade objetiva ou subjetiva são analisadas no momento em que o julgador deve definir qual o limite e os elementos que vincularão a vítima ao culpado pelo infortúnio, no caso de acidentes de trabalho ou doenças profissionais a eles equiparados.

A sociedade de maneira geral carece de soluções práticas para vários problemas que se relacionam ao dever do empregador de indenizar seus funcionários nestas ações e, a partir da configuração da responsabilidade civil o objetivo da pesquisa foi identificar qual(is) a(s) teoria(s) predominante(s) na jurisprudência dos tribunais.

METODOLOGIA

O trabalho se apoiou em pesquisas bibliográficas, fichamentos, legislação em vigor e doutrina nacional trabalhista. Os conceitos teóricos foram examinados pelo método hipotéticodedutivo, onde a investigação geral se iniciou no âmbito do Direito Civil, pioneira na matéria, para o particular, ou seja, focou o instituto na esfera trabalhista. As informações sobre o tema foram analisadas e confrontadas de forma dialética, de modo a entender qual a corrente de pensamento dominante na atualidade.

\section{RESULTADOS}

Verifica-se com essa pesquisa que em relação as teorias seguidas pelo Tribunal Superior do Trabalho os juízes no caso concreto analisando as provas trazidas no processo, definem qual teoria deve ser adotada, visto que em alguns tribunais o mesmo juiz adota tanto a teoria objetiva como a subjetiva.

\section{DISCUSSÃO}

A palavra responsabilidade deriva do latim, do verbo respondere, aquele que garante algo, ou responde por algo.

Mas difícil seria enquadrar o conceito de responsabilidade nessa relação em que somente o causador do dano é aquele que age e, em tese, será responsabilizado.

O que realmente importa é a circunstância da infração da norma ou obrigação do agente.

Conforme a lição precisa de Silvio Rodrigues $(2002$, p. 6):

Realmente o problema em foco é o de saber se o prejuízo experimentado pela vítima deve ou não ser reparado por quem o causou. Se a resposta for afirmativa, cumpre indagar em que condições e de que maneira será tal prejuízo reparado. Esse é o campo que a teoria da responsabilidade civil procura cobrir.

Pela divergência do tema, grande dificuldade a doutrina tem enfrentado para conceituar responsabilidade civil. Alguns autores conceituam a responsabilidade civil levando apenas em consideração a culpa. Outros pelas consequências prejudiciais de suas ações e ainda há os que levam não só a culpa em consideração, englobando, também, o risco criado.

Assim, conforme Maria Helena Diniz (2003, p. 36) o conceito de responsabilidade civil se define como:

A aplicação de medidas que obriguem alguém a reparar o dano moral ou patrimonial causado a terceiros em razão de ato do próprio imputado, de pessoa por quem ele responde, ou de fato de coisa ou animal sob sua guarda (responsabilidade subjetiva), ou, ainda, de simples imposição legal (responsabilidade objetiva). Definição esta que guarda, em sua estrutura, a 
ideia da culpa quando se cogita da existência de ilícito e a do risco, ou seja, da responsabilidade sem culpa.

Nesse contexto, quando alguém comete um ato ilícito, este deve ser reparado.

A responsabilidade civil é conceituada por Álvaro Villaça de Azevedo (2004, p. 277), como "[...] a situação de indenizar o dano moral ou patrimonial, decorrente de inadimplemento culposo, de obrigação legal ou contratual, ou imposta por lei, ou, ainda, decorrente do risco para os direitos de outrem".

De forma sintética, a obrigação de indenizar é decorrente de uma responsabilidade civil do agente que, agindo com culpa, tem tal obrigação, imposta por lei ou contratual, (ou até mesmo decorrente do risco que uma atividade), pela ocorrência de danos: material, estético ou moral.

No que se refere à responsabilidade civil, o artigo 186 do Código Civil a define como existente quando: "Art. 186. Aquele que por ação ou omissão voluntária, negligência ou imprudência, violar direito e causar dano a outrem, ainda que exclusivamente moral, comete ato ilícito" (CONGRESSO NACIONAL, 2002, p. 1).

Ora, o que se verifica é a preponderância da presença da responsabilidade dita subjetiva em nosso ordenamento, pois manteve a culpa como fundamento para o direito da vítima de ser indenizada quanto a eventual dano moral, decorrente da responsabilidade civil do agressor.

Assim, aquele que comete ato ilícito fica obrigado a reparar o dano, tanto material quanto moral.

Conforme Carlos Roberto Gonçalves (2003, p. 21), a responsabilidade é subjetiva quando depende da existência de culpa, sendo a prova de sua existência pressuposto indispensável para configurar o dano indenizável. Assim, a responsabilidade do causador do dano apenas se configura se este agiu com dolo ou culpa.

A responsabilidade subjetiva se funda no pressuposto culpa. Para que esta se configure o agente precisa provar que, por sua culpa, causou aquele dano.

Nessa linha, o doutrinador Sérgio Cavalieri Filho (2005, p. 39-40):

Por essa concepção clássica, todavia a vítima só obterá a reparação do dano se provar a culpa do agente, o que nem sempre é possível na sociedade moderna. O desenvolvimento industrial, proporcionado pelo advento do maquinismo e outros inventos tecnológicos, bem como o crescimento populacional geraram novas situações que não podiam ser amparadas pelo conceito tradicional de culpa.

Aduz Fábio Ulhoa Coelho (2004, p. 259) que:

Em última instância, a imputação de responsabilidade ao culpado, pelo evento danoso fundamenta-se na noção da vontade como fonte da obrigação. A ação ou omissão negligente, imprudente ou imperícia ou mesmo intenção de causar dano correspondem à conduta diversa da juridicamente exigível. A exigibilidade de conduta diversa pressupõe pelo menos duas alternativas abertas à vontade (consciente ou inconsciente) do sujeito passivo. Se o devedor agiu como não deveria, o fez por ato de vontade.

Destarte, com o avanço e a modernidade, a culpa não passa a ser essencial para o ensejo da responsabilidade, revelando-se assim, uma responsabilidade pela culpa presumida ou risco da atividade (objetiva propriamente dita ou pura). 
Para a responsabilidade objetiva o fator culpa é irrelevante. É necessária apenas a presença dos elementos: nexo causal e o dano para que haja a responsabilidade. A culpa é presumida, ficando a vítima obrigada a provar somente a ação ou omissão do agente e o dano causado.

Algumas excludentes podem ser alegadas, tais como: culpa exclusiva da vítima ou força maior. Nada sendo provado em relação às excludentes a responsabilidade recai sobre o agente, pois sua culpa se presume. É o que acontece, por exemplo, no artigo 936 do Código Civil, em relação ao dono de animal que venha causar dano a outrem, presume-se culpado (CONGRESSO NACIONAL, 2002, p.1).

Por outro lado a teoria do risco se insere e se materializa quando o risco de algumas atividades é acentuado, gerando responsabilidade. O que importa é a atividade ou conduta do agente resultante da exposição a um perigo, pela natureza da atividade ou por seus meios adotados, justificando o dever de indenizar, até mesmo não existindo o nexo causal.

Sobre a teoria do risco, Carlos Roberto Gonçalves nos ensina que (2003, p. 22):

[...] Para esta teoria, toda pessoa que exerce uma atividade cria um risco de dano para terceiros. E deve ser obrigada a repará-lo, ainda que sua conduta seja isenta de culpa. A responsabilidade civil desloca-se da noção de culpa para a ideia de risco, ora encarada como "risco-proveito", que se funda no princípio segundo o qual é reparável o dano causado a outrem em consequência de uma atividade realizada em benefício do responsável (ubi emolumentum, ibi ônus); ora mais genericamente como "risco criado", a que se subordina todo aquele que, sem indagação de culpa, expuser alguém a suportá-lo.

Já em relação à diferença entre a responsabilidade objetiva e subjetiva, Christiano Cassetari (2006, p. 111-112) destaca que:

Subjetiva - É a regra no nosso ordenamento civil. Quando a responsabilidade civil for subjetiva será necessária a prova da existência da culpa ou do dolo.

Objetiva - Atribuída ao agente independentemente de culpa. Esse tipo de responsabilidade é especificada cada em lei, ou se dará quando a atividade normalmente desenvolvida pelo autor do dano importar em riscos para os direitos de outrem (Teoria do risco).

Assim quando a atividade normalmente desenvolvida pelo autor do dano importar em riscos para os direitos de outrem caberá a indenização. Neste caso cabe à doutrina e jurisprudência definir o que vem a ser atividade de risco.

Em sede de responsabilidade civil, a primeira ideia de responsabilidade ou regra básica é que cada um responda por seus atos, exclusivamente pelo que fez e por sua conduta própria. Trata-se da responsabilidade civil direta em que por ato próprio, o agente do dano é responsável por sua reparação.

Maria Helena Diniz (2003, p. 461) conceitua o que vem a ser responsabilidade civil direta: "A responsabilidade direta ou por fato próprio é a que decorre de um fato pessoal do causador do dano, ou seja, de uma ação direta de uma pessoa ligada à violação ao direito ou ao patrimônio, por ato culposo ou doloso".

Além disso, se todos os causadores de danos, unicamente fossem responsáveis pela indenização, muitos prejuízos ficariam sem ressarcimento.

Por isso, a lei admite excepcionalmente que outra pessoa responda por fato de outrem, embora esta não tenha concorrido diretamente pelo evento danoso. Trata-se da responsabilidade civil indireta. 
A respeito da responsabilidade civil indireta Sérgio Cavalieri Filho (2005, p. 200) destaca:

Isso, entretanto, não ocorre arbitrária e indiscriminadamente. Para que a responsabilidade desborde do autor material do dano, alcançando alguém que não concorreu diretamente para ele, é preciso que esse alguém esteja ligado por algum vínculo jurídico ao autor do ato ilícito, de sorte a resultarIhe, daí, um dever de guarda, vigilância ou custódia.

Deste ensinamento, concluímos que a responsabilidade civil indireta é na verdade uma garantia à vítima, pois, caso o agente do dano não possa arcar com suas obrigações, deve-se buscar outros responsáveis que tenham, legalmente, o dever de vigiar a conduta do agente. É o que acontece nos casos expressos do artigo 932 do Código Civil, que dentre outros, estabelece em seu inciso III que também respondem pela reparação civil "o empregador ou comitente, por seus empregados, serviçais e prepostos, no exercício do trabalho que lhes competir, ou em razão dele" (CONGRESSO NACIONAL, 2002, p.1).

Sendo assim, a responsabilidade por fato de outrem se constitui pela infração do dever de vigilância, pela violação desse dever. Porém a vítima não está obrigada a acionar o responsável pela vigilância. Ele pode pedir indenização contra o agente causador direto, se lhe for conveniente. Ocorre que, na prática, muitas vezes esses agentes não possuem patrimônio suficiente para suportar o prejuízo.

Com o Novo Código Civil de 2002, a presunção relativa foi afastada, criando, então, a responsabilidade objetiva, calcada na teoria do risco.

Nesse sentido Sérgio Cavalieri Filho exemplifica (2005, p. 203):

[..] De onde se conclui que na responsabilidade pelo fato de outrem há na realidade, o concurso de duas responsabilidades: a do comitente ou patrão e a do proposto. A do primeiro é objetiva, porque o comitente é garantidor ou assegurador das consequências danosas dos atos do seu agente; a do segundo é subjetiva, porque, embora desnecessária a culpa do civilmente responsável (comitente), é indispensável em relação ao agente, autor do fato material (preposto, agente etc.). Destarte, só indiretamente se pode dizer que a responsabilidade por fato de outrem repousa na culpa. Ambos, entretanto- responsável e agente- respondem solidariamente perante a vítima (Código Civil, art. 942, parágrafo único).

Logo, a responsabilidade por fato de outrem é agora objetiva, não mais com culpa presumida. Concluímos que tanto o agente quanto o responsável são solidariamente responsáveis.

Após esta breve análise das teorias existentes, cumpre verificar quais, na esfera trabalhista, prevalecem nas causas acidentárias.

A fim de obter reparação dos danos causados ao trabalhador, em todas as suas espécies (moral, material, estético), em decorrência dos acidentes de trabalho e doenças do trabalho e profissionais, equiparadas ao acidente para esses fins, o tema da responsabilidade civil, subjetiva a princípio e objetiva em atividades de risco, o tema ganhou vulto na seara trabalhista pois, a partir da Emenda 45/2004, passou para a Justiça do Trabalho a competência para processar e julgar tais demandas.

Com esta alteração de competência surge uma nova visão no ordenamento jurídico trabalhista. Tantos nos tribunais regionais do trabalho como no Tribunal Superior do Trabalho (TST), vários casos concretos foram analisados com apoio nessas teorias.

Por exemplo, utilizando a teoria subjetiva, que investiga a culpa patronal, interessante ementa do TRT (Tribunal Regional do Trabalho) paranaense concluiu: 
TRT-PR-16-11-2011 ACIDENTE DO TRABALHO. APLICAÇÃO DA TEORIA SUBJETIVA DA RESPONSABILIDADE CIVIL. Com fundamento no art. 5ㅇ, $\mathrm{V}$ e X, e 7으, XXVIII, da CF, e nos arts. 186, 187 e 927, do CCB, é possível afirmar que o nosso ordenamento jurídico adotou como regra a responsabilidade civil subjetiva - que depende da prova de dano, ato doloso ou culposo e nexo de causalidade[..]. Recurso da ré a que se dá provimento. (TRT-9 995042005562900 PR 99504-2005-562-9-0-0, Relator: SUELI GIL EL-RAFIHI, 4A. TURMA, Data de Publicação: 16/11/2011)

A maioria dos ministros do Tribunal Superior do Trabalho, a mais alta Corte na esfera trabalhista, também têm adotado a teoria subjetiva pura, baseada na comprovação da culpa, empresarial, concorrente, ou exclusiva do trabalhador vitimado, a par do crescimento da teoria objetiva ou do risco criado.

Comprova a afirmação, a ementa a seguir reproduzida:

RECURSO DE REVISTA. RESPONSABILIDADE CIVIL. INDENIZAÇÃO POR DANO MORAL E MATERIAL DECORRENTE DE ACIDENTE DE TRABALHO. RESPONSABILIDADE SUBJETIVA DO EMPREGADOR CARACTERIZADA. O artigo 7으, XXVIII, da Constituição Federal consagra a responsabilidade subjetiva do empregador pelos danos decorrentes de acidente de trabalho sofrido pelo empregado. Na hipótese, a Corte de origem registrou que o acidente de trabalho não ocorreu por culpa do autor, mas por "imperícia do motorista que calculou mal a manobra" do ônibus de passageiros. Recurso de revista de que não se conhece. [..] (TST - RR: 1388009420055070007, Relator: Cláudio Mascarenhas Brandão, Data de Julgamento: 25/03/2015, 7̣a Turma, Data de Publicação: DEJT 31/03/2015)

Mas ganha força a corrente que utiliza a teoria objetiva para condenar os empregadores nas indenizações por danos morais e materiais decorrentes dos acidentes de trabalho e, por via de consequência materializando a responsabilidade civil do empregador, independentemente de culpa.

Neste sentido, ilustrativa é a ementa do TST:

DANOS MORAIS E MATERIAIS. RESPONSABILIDADE OBJETIVA. ACIDENTE DE TRÂNSITO. MOTORISTA DE ÔNIBUS. 1. O novo Código Civil Brasileiro manteve, como regra, a teoria da responsabilidade civil subjetiva, calcada na culpa. Inovando, porém, em relação ao Código Civil de 1916, ampliou as hipóteses de responsabilidade civil objetiva, acrescendo aquela fundada no risco da atividade empresarial. [..]. 3. Recurso de Revista conhecido e provido. (TST - RR: 764005120065150083Data de Julgamento: 30/09/2015, Data de Publicação: DEJT 02/10/2015)

Como pode ser confrontado nas ementas colacionadas, ambas as teorias, tem aplicação nos tribunais nos casos concretos.

\section{CONCLUSÃO}

Embora tamanha seja a controvérsia existente e as dúvidas dos aplicadores do Direito sobre o tema, pôde-se concluir que a teoria que predomina no Tribunal Superior do Trabalho (TST), é a subjetiva, onde se investiga a culpa. 
Contudo, em alguns setores da economia, que trabalham em atividade de risco, é utilizada a teoria objetiva. Nesta teoria não é necessária a prova da culpa empresarial, direta ou indireta (dano praticado pelo próprio empregador ou seus representantes, os chamados prepostos).

O reconhecimento da teoria objetiva resguarda o trabalhador sem afrontar qualquer dispositivo constitucional, já que assegura a prevalência da dignidade humana, a proteção ao trabalhador, e o valor social do trabalho, garantindo a supremacia da Constituição e a observância de seus princípios.

Não se descarta, contudo, o direito que o empregador também tem de provar se houve ou não sua culpa pelo infortúnio, preservando o princípio da igualdade, constitucionalmente garantido a todos (teoria subjetiva), a exceção dos casos em que, pela atividade econômica desenvolvida: de risco, responderá independentemente de culpa.

\section{REFERÊNCIAS}

AZEVEDO, Álvaro Villaça. Teoria Geral das Obrigações: responsabilidade civil. 10a ed. São Paulo: Atlas, 2004.

BRASIL. Congresso Nacional. Código Civil. Lei n. 10.406, de 10 de janeiro de 2002. Institui o Código Civil. Diário Oficial da União, Brasília, DF, 11 jan. 2002. Disponível em: <http://www.planalto.gov.br/ccivil_03/leis/2002/L10406.htm>. Acesso em: 09 set. 2016.

BRASIL. TRT. (9. Região). TRT-PR-16-11-2011 acidente do trabalho. Aplicação da teoria subjetiva da responsabilidade civil. Relator: Sueli Gil El-Rafihi. Curitiba, 16 nov. 2011. Disponível em: <http://trt-9.jusbrasil.com.br/jurisprudencia/20757344/995042005562900-pr-99504-2005-562-90-0-trt-9>. Acesso em: 09 set. 2016.

BRASIL. TST. Danos Morais E Materiais. Responsabilidade objetiva. Acidente de trânsito. Motorista de ônibus [...]. Recurso de Revista n. 764005120065150083. Recorrente Osvaldo Gomes de oliveira e Recorrida empresa de Ônibus São Bento Ltda. Relator: Marcelo Lamego Pertence. Brasília, 30 set. 2015. Disponível em: <http://tst.jusbrasil.com.br/jurisprudencia/239019886/recurso-derevista-rr-764005120065150083>. Acesso em: 09 set. 2016.

BRASIL. TST. Recurso de revista. Responsabilidade civil. Indenização por dano moral e material decorrente de acidente de trabalho. Responsabilidade subjetiva do empregador caracterizada [...]. Recurso de Revista n. 1388009420055070007. Recorrente Maraponga Transportes Ltda e Recorrido José Sebastião Soares. Relator: Cláudio Mascarenhas Brandão. Brasília, 25 de março de 2015. Disponível em: <http://tst.jusbrasil.com.br/jurisprudencia/178317228/recurso-de-revista-rr$1388009420055070007>$. Acesso em 09 set. 2016.

CASSETTARI, Christiano. Elementos do Direito. Direito Civil. São Paulo: Premier Máxima, 2006.

CAVALIERI FILHO, Sérgio. Programa de Responsabilidade Civil. 6a ed., revista aumentada. São Paulo: Malheiros, 2005.

COELHO, Fábio Ulhoa. Curso de Direito Civil. São Paulo: Saraiva, 2004, v.2.

DIAS, José de Aguiar. Da responsabilidade civil. 11aㅡ ed., revista atualizada de acordo com o Código Civil de 2002, e aumentada por Rui Berford Dias. Rio de Janeiro: Renovar, 2006. 
DINIZ, Maria Helena. Curso de Direito Civil Brasileiro: responsabilidade civil. 17ạ ed. São Paulo: Saraiva, 2003, v.3.

GLAGLIANO, Pablo Stolze. PAMPLONA FILHO, Rodolfo. Novo Curso de Direito Civil: responsabilidade civil. São Paulo: Saraiva, 2003, v.3.

GONÇALVES, Carlos Roberto. Responsabilidade Civil: revista de acordo com o novo Código Civil (Lei n. 10.406 de 10-1-2002). 8a ed. São Paulo: Saraiva, 2003.

MONTEIRO, Washington de Barros. Curso de Direito Civil: direito das obrigações 2a parte. 34 a ed. Ver. E Atual. Por Carlos Alberto Dabus Maluf e Regina Beatriz Tavares da Silva. São Paulo: Saraiva, 2003, v.5.

PEREIRA, Caio Mário da Silva. Instituições de Direito Civil: revista e atualizada por Regis Fichtner. 11 a ed. Rio de Janeiro: Forense, 2003, v.3.

PINTO, Eduardo Viana. Responsabilidade Civil: de acordo com o Novo Código Civil. 1a ed. Porto Alegre: Síntese, 2003.

RODRIGUES, Silvio. Direito Civil: responsabilidade civil. 19a ed. São Paulo: Atlas, 2006.

TARTUCE, Flávio. Direito Civil: direito das obrigações e responsabilidade civil. 3ạ ed. São Paulo: Método, 2008, v. 2.

VENOSA, Silvio de Salvo. Direito Civil: responsabilidade civil. 4ạ ed. São Paulo: Atlas S.A, 2004, v.4. 